\title{
Lipopolysaccharide-induced memory impairment in rats is preventable using 7-nitroindazole
}

\author{
0 déficit de memória induzido por lipossacarídeos em ratos é prevenido por nitroindazol \\ Akbar Anaeigoudari', Mohammad Naser Shafei', Mohammad Soukhtanloo², Hamid Reza Sadeghnia², \\ Parham Reisi ${ }^{4}$, Farimah Beheshti ${ }^{1}$, Reza Mohebbati ${ }^{5}$, Seyed Mojtaba Mousavi ${ }^{5}$, Mahmoud Hosseini ${ }^{5}$
}

\begin{abstract}
Inflammation and oxidative stress have important roles in memory impairment. The effect of 7-nitroindazole (7NI) on lipopolysaccharide (LPS)-induced memory impairment was investigated. Rats were used, divided into four groups that were treated as follows: (1) control (saline); (2) LPS; (3) 7NI-LPS; and (4) 7NI before passive avoidance (PA). In the LPS group, the latency for entering the dark compartment was shorter than in the controls $(p<0.01$ and $p<0.001)$; while in the $7 \mathrm{NI}$-LPS group, it was longer than in the LPS group ( $<0.01$ and $p<0.001)$. Malondialdehyde (MDA) and nitric oxide (NO) metabolite concentrations in the brain tissues of the LPS group were higher than in the controls ( $p<0.001$ and $p<0.05$ ); while in the 7NI-LPS group, they were lower than in the LPS group $(p<0.001$ and $p<0.05$, respectively). The thiol content in the brain of the LPS group was lower than in the controls $(p<0.001)$; while in the $7 \mathrm{NI}-\mathrm{LPS}$ group, it was higher than in the LPS group ( $p$ 0.001). It is suggested that brain tissue oxidative damage and NO elevation have a role in the deleterious effects of LPS on memory retention that are preventable using $7 \mathrm{NI}$.
\end{abstract}

Keywords: learning, memory, lipopolysaccharide, $7 \mathrm{NI}$.

\section{RESUMO}

Inflamação e estresse oxidativo tem importante papel no déficit de memória. O efeito do 7-nitroindazol (7NI) no déficit de memória induzido por lipossacarídeos (LPS) foi investigado. Foram utilizados ratos que foram divididos em quatro grupos e tratados da seguinte maneira: (1) controles (solução salina); (2) LPS; (3) 7NI-LPS; e (4) 7NI antes da esquiva passiva (PA). No grupo LPS, a latência para entrar no compartimento escuro foi mais curta que nos controles ( $p<0,01$ e $p<0,001$ ); enquanto no grupo $7 \mathrm{NI}$-LPS, a latência foi maior que aquela do grupo LPS ( $p<0,01$ e $p<0,001$ ). Concentrações de malondialdeído (MDA) e metabólitos do ácido nítrico (NO) no tecido cerebral do grupo LPS foram maiores que aquelas dos controles ( $p<0,001$ e $p<0,05$ ); enquanto no grupo 7NI-LPS, as concentrações foram menores do que no grupo LPS ( $p<0,001$ e $p<0,05$, respectivamente). O conteúdo cerebral de tiol no grupo LPS foi menos do que nos controles ( $p<0,001)$; enquanto no grupo 7NI-LPS, este conteúdo foi maior que no grupo LPS ( $p<0,001)$. Sugere-se que o dano oxidativo cerebral e o aumento de NO tenham um papel nos efeitos deteriorativos dos LPS na memória de retenção, e que isto possa ser prevenido com o uso de $7 \mathrm{NI}$.

Palavras-chave: aprendizado, memória, lipopolissacarídeo, 7NI.

A large number of individuals in the world particularly the elderly people suffer from different degrees of learning and memory impairments. Although precise causes have remained unknown until now, inflammation and oxidative stress may at least in part be responsible for learning and memory deficits ${ }^{1}$. Systemic inflammation promotes the production of various cytokines such as tumor necrosis factors- $\alpha$ (TNF- $\alpha$ ), interleukin-1 $\beta$ (IL-1 $\beta$ ) and IL-6 in the brain. It is documented that TNF- $\alpha$ impairs spatial learning and memory, when it is administrated intracerebroventricularly before water maze training. In addition, injection of TNF- $\alpha$ into the hippocampus disrupted hippocampal-dependent working memory which was indicated by an enhanced number of errors and longer latencies to perform the three-panel runway $\operatorname{task}^{2}$. In human also inflammation is considered to contribute in pathogenesis disorders including Alzheimer's disease (AD), Parkinson disease, multiple sclerosis ${ }^{3}$ and epilepsy ${ }^{4}$. In multiple animal models, exposure to immune system stimulating

\footnotetext{
${ }^{1}$ Neurocognitive Research Center, School of Medicine, Mashhad University of Medical Sciences, Mashhad, Iran;

${ }^{2}$ Department of Biochemistry, School of Medicine, Mashhad University of Medical Sciences, Mashhad, Iran;

${ }^{3}$ Pharmacological Research Center of Medicinal Plants, School of Medicine, Mashhad University of Medical Sciences, Mashhad, Iran;

${ }^{4}$ Department of Physiology, School of Medicine, Isfahan University of Medical Sciences, Isfahan, Iran;

${ }^{5}$ Neurogenic Inflammation Research Center, School of Medicine, Mashhad University of Medical Sciences, Mashhad, Iran.

Correspondence: Mahmoud Hosseini; Neurocognitive Research Center and Department of Physiology, School of Medicine, Mashhad University of Medical Sciences, Mashhad, Iran Mashhad 9177948564, Islamic Republic of Iran; E-mail: hosseinim@mums.ac.ir

Conflict of interest: There is no conflict of interest to declare.

Received 30 October 2014; Received in final form 30 April 2015; Accepted 20 May 2015.
} 
pathogens such as viral and bacterial or viral coat proteins and bacterial endotoxins results in learning and memory deficits $^{2}$. Lipopolysaccharide (LPS) obtained from the cell wall of gram-negative bacteria has been shown that promotes the production of inflammatory cytokines that in turn lead to excessive production of free radicals and oxidative stress. Intraperitoneal injection of LPS also leads to neuroinflammation, hippocampus apoptosis, cognitive deficits and learning and memory impairments ${ }^{5}$.

Nitric oxide (NO) is a diffusible gaseous messenger which synthesized from amino acid L-arginine by the three different isoforms of nitric oxide synthase (NOS) including; neuronal NOS (nNOS), inducible NOS (iNOS) and endothelial NOS (eNOS). The nNOS is expressed in the neurons of the cerebellum, hypothalamus, striatum, cerebral cortex and hippocampus as well as in the astrocytes. In the brain of individuals with $\mathrm{AD}, \mathrm{nNOS}$ is aberrantly expressed in vulnerable pyramidal cells, astrocytes and nerve cells ${ }^{6,7}$. In physiological concentrations, NO plays a neuroprotective role in the nervous system whereas, it promotes apoptosis and cell death in high concentrations through stimulating of the superoxide anion formation in the mitochondria ${ }^{8}$. It has been suggested that overproductions of NO take place due to activation of nNOS by the stimuli such as endotoxins and cytokines ${ }^{9}$. It has also been reported that both nNOS and eNOS isoforms affect learning and memory ${ }^{10}$.

7-nitroindazol (7NI) has been considered as a selective nNOS inhibitor as well as a nonselective NOS inhibitors (nNOS/eNOS $)^{10,11}$. It has been shown that 7NI induces learning and memory deficits in different behavioral experiments such as, Morris water maze(MWM), radial maze, passive avoidance (PA) and elevated plus maze tests ${ }^{12}$.

Researchers have reported that LPS increases the production of mediators such as NO, prostaglandin E2 (PGE2) and reactive oxygen species (ROS) through stimulating the macrophages ${ }^{13}$. LPS also increases the level of NO through promoting the release of pro-inflammatory cytokines such as TNF- $\alpha$ and IL-1 $\beta$ from macrophages and leucocytes ${ }^{14}$. It has been reported that the direct intracerebral injection of LPS increases the levels of NO metabolites in the brain which is prevented by NOS inhibitors particularly iNOS inhibitors such as aminoguanidine ${ }^{15}$. Despite these reports the aim of this study was further evaluation of the effect of $7 \mathrm{NI}$ in LPS-induced memory impairment.

\section{METHOD}

\section{Animals and drugs}

Thirty-six male Wistar rats (8 weeks old and $200-250 \mathrm{~g}$ weight) were kept in standard conditions $\left(22 \pm 2^{\circ} \mathrm{C}\right.$ temperature and $12 \mathrm{~h}$ light/dark cycle). Working with the animals was conducted in accordance with procedures approved by Mashhad Medical University Committee on Animal
Research (NO: A.H/1393/380). The animals were divided into four groups: (1) control (2) LPS, (3) 7NI-LPS and (4) 7NI ( $n=9-10$ in each group). LPS was dissolved in saline and injected ( $1 \mathrm{mg} / \mathrm{kg}$; i.p.) $2 \mathrm{~h}$ before retention trail. 7NI was dissolved in saline supplemented with $3 \%$ dimethyl sulfoxide (DMSO) and injected (30 mg/kg; i.p.) 30 minutes before LPS or saline in 7NI-LPS and 7NI groups respectively. In the LPS group, the animals were injected by saline supplemented with $3 \%$ DMSO $(2 \mathrm{~mL} / \mathrm{kg})$ instead of $7 \mathrm{NI}$. The control and $7 \mathrm{NI}$ groups received $2 \mathrm{~mL} / \mathrm{kg}$ of saline instead of LPS. LPS and 7NI were purchased from Sigma (Sigma Aldrich Chemical Co.). Other chemicals such as DMSO and those which were used for biochemical assessments were purchased from Merck Company.

\section{Passive avoidance (PA) test}

PA apparatus is included of light and dark compartments separated by a guillotine door. In pre-acquisition trial, the animals were placed individually into the light compartment, the door was opened and the animals were allowed to explore the compartments for $300 \mathrm{~s}$ during two consecutive days. In the training trail, the rats were placed in the light compartment, the door was opened after $15 \mathrm{~s}$ and the latencies to enter the dark compartment were recorded. When the animals were entered completely into the dark compartment, the door was closed and an electrical shock ( $2 \mathrm{~mA}, 2 \mathrm{~s}$ ) was delivered to the floor of the compartment. At 3, 24, 48 and $72 \mathrm{~h}$ later, the animals were again located in the light compartment for $15 \mathrm{~s}$, after opening the guillotine door they gave access to the dark compartment within a period of $300 \mathrm{~s}$. Then the time latency to enter into the dark room as well as the time spent by the animals in the light and dark compartments were recorded and defined as retention trail ${ }^{16,17}$.

\section{Biochemical assessment}

The animals were sacrificed after a deep anesthesia, the brains were removed, weighed, and submitted to determine of total thiol (SH) content, malondialdehyde (MDA), and NO metabolites $\left(\mathrm{NO}_{2}\right.$ or $\left.\mathrm{NO}_{3}\right)$ concentrations and the activity of superoxide dismutase (SOD).

\section{MDA assessment}

MDA level is as an index of lipid peroxidation. MDA reacts with thiobarbituric acid (TBA) as a TBA reactive substance (TBARS) and produces a red complex. Briefly, $1 \mathrm{~mL}$ of the brain homogenates was added to $2 \mathrm{~mL}$ of a complex solution containing TBA/trichloroacetic acid (TCA)/hydrochloric acid (HCL) and it was then boiled in a water bath for 40 minutes. After reaching to the room temperature, the solution was centrifuged at $1000 \mathrm{~g}$ for 10 minutes. The absorbance was read at $535 \mathrm{~nm}$. The MDA concentration was calculated according to follow equation ${ }^{18}$. 


\section{Determination of total thiol contents}

DTNB (2, 2'-dinitro-5, 5'-dithiodibenzoic acid) reagent which reacts with the SH group, was used to determine the total thiol contents. The produced yellow complex has a peak absorbance at $412 \mathrm{~nm}$. In brief, $50 \mu \mathrm{L}$ of tissue homogenates were added to $1 \mathrm{~mL}$ Tris-EDTA) ethylenediaminetetraacetic acid) buffer $(\mathrm{pH}=8.6)$ and the absorbance was read at $412 \mathrm{~nm}$ against Tris-EDTA buffer alone (A1). Then, $20 \mu \mathrm{L}$ of $10 \mathrm{mM}$ solution of DTNB were mixed with the solution and it was stored in room temperature for 15 minutes and the absorbance was read again (A2). The absorbance of DTNB reagent was also read as a blank (B). Total thiol concentration $(\mathrm{mM})$ was calculated as follow equation ${ }^{18}$.

Total thiol concentration

$(\mathrm{mM})=(\mathrm{A} 2-\mathrm{A} 1-\mathrm{B}) \times 1.07 / 0.05 \times 13.6$

\section{Determination of $\mathrm{NO}$ metabolites $\left(\mathrm{NO}_{2} / \mathrm{NO}_{3}\right)$}

The Griess reaction was used to assay NO metabolites. Briefly, standard curves for nitrates (Sigma St. Louis, Missouri, USA) were prepared, and the samples ( $100 \mu \mathrm{L}$ the tissue suspension) were added to the Griess reagent. The proteins were subsequently precipitated by addition of $50 \mu \mathrm{L}$ of $10 \%$ TCA. The contents were then vortex-mixed and centrifuged, and the supernatants were transferred to a 96-well flat-bottomed microplate. Absorbance was read at $520 \mathrm{~nm}$ using a microplate reader, and the final values were calculated from standard calibration plots ${ }^{19,20}$.

\section{Determination of SOD activity}

SOD activity was measured by the procedure described by Madesh and Balasubramanian. A colorimetric assay involving generation of superoxide by pyrogallol auto-oxidation and the inhibition of superoxide-dependent reduction of the tetrazolium dye, MTT (3-(4, 5-dimethylthiazol-2-yl) 2,5-diphenyltetrazolium bromide) to its formazan by SOD was measured at $570 \mathrm{~nm}$. One unit of SOD activity was defined as the amount of enzyme causing 50\% inhibition in the MTT reduction rate.

\section{Statistical analysis}

All data were expressed as means \pm SEM. The data were evaluated by two-way ANOVA. There were two groups (control $\times$ LPS) and two treatments (Vehicle $\times 7 \mathrm{NI})$. Differences were considered statistically significant when $\mathrm{p}<0.05$.

\section{RESULTS}

\section{PA results}

The results showed that there were no significant differences before receiving the shock in the latency for entering the dark compartment between the groups. Using two way ANOVA, the results showed that there was also a significant main effects for LPS on latency to enter the dark compartment at all 3( $\left.\mathrm{f}_{(1,35)}=336.166 ; \mathrm{p}<0.001\right)$, $24\left(\mathrm{f}_{(1,30)}=43.51 ; \mathrm{p}<0.001\right), 48\left(\mathrm{f}_{(1,35)}=37.58 ; \mathrm{p}<0.001\right)$ and $72\left(\mathrm{f}_{(1,35)}=19.66 ; \mathrm{p}<0.001\right)$ hours after receiving shock. 7NI also significantly affected latency to enter the dark compartment at all $3\left(\mathrm{f}_{(1.35)}=336.166 ; \mathrm{p}<0.001\right)$, $24\left(\mathrm{f}_{(1,35)}=22.66 ; \mathrm{p}<0.001\right), 48\left(\mathrm{f}_{(1,35)}=18.207 ; \mathrm{p}<0.001\right)$ and $72\left(\mathrm{f}_{(1,35)}=18.76 ; \mathrm{p}<0.001\right)$ hours after receiving shock. There was a significant interaction between $7 \mathrm{NI}$ and LPS on latency to enter the dark compartment at all 3( $\left.f_{(1,35)}=336.166 ; p<0.001\right), 24\left(f_{(1,35)}=20.18 ; p<0.001\right)$, $48\left(\mathrm{f}_{(1,35)}=16.16 ; \mathrm{p}<0.001\right)$ and $72\left(\mathrm{f}_{(1,35)}=8.13 ; \mathrm{p}<0.01\right)$ hours after receiving shock. The results also showed that the latency to enter the dark compartment in LPS group was significantly lower control group at 3, 24, 48 and 72 hours after receiving shock $(\mathrm{p}<0.001$ and $\mathrm{p}<0.01)$. The latencyin 7NI-LPS and 7NI groups was longer than LPS group $(\mathrm{p}<0.001$ and $\mathrm{p}<0.01)$. There was no significant difference between control, 7NI and 7NI-LPS groups (Figure 1).

Using two way ANOVA, the results showed that there was also a significant main effects for LPS on the total time spent in dark compartment at all $3\left(\mathrm{f}_{(1,35)}=19.13\right.$; $\left.\mathrm{p}<0.001\right)$, $24\left(\mathrm{f}_{(1,35)}=7.71 ; \mathrm{p}<0.01\right), 48\left(\mathrm{f}_{(1,35)}=10.47 ; \mathrm{p}<0.01\right)$ and $72\left(\mathrm{f}_{(1,35)}=18.80 ; \mathrm{p}<0.001\right)$ hours after receiving the shock. $7 \mathrm{NI}$ also significantly affected the total time spent in dark compartment at all $3\left(\mathrm{f}_{(1,35)}=19.13 ; \mathrm{p}<0.001\right), 24\left(\mathrm{f}_{(1,35)}=6.18\right.$; $\mathrm{p}<0.01), 48\left(\mathrm{f}_{(1,35)}=5.56 ; \mathrm{p}<0.05\right)$ and $72\left(\mathrm{f}_{(1,35)}=10.68 ; \mathrm{p}<0.01\right)$ hours after receiving the shock. There was a significant interaction between 7NI and LPS on the total time spent in dark

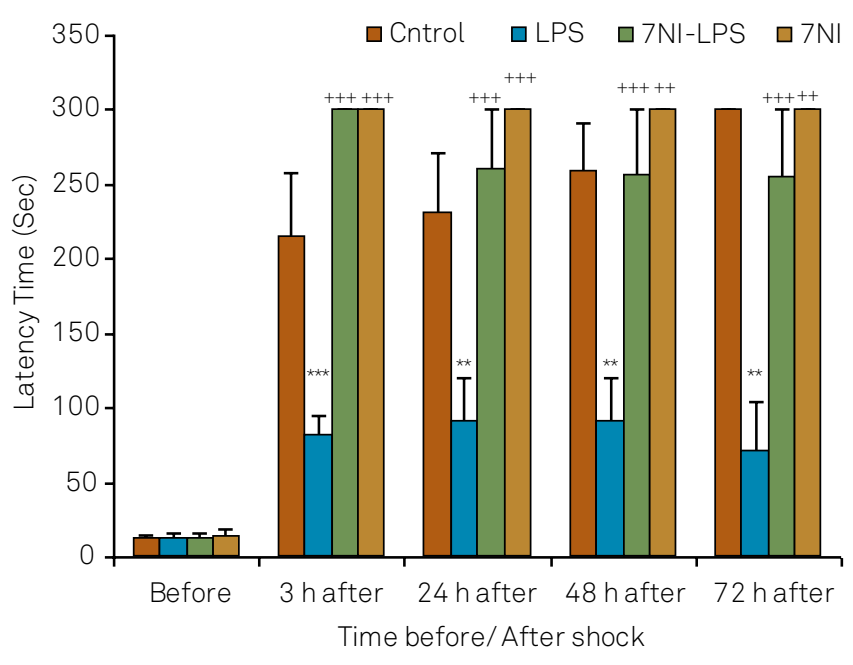

LPS: lipopolysaccharide; 7N1:7-nitroindazole.

Figure 1. Comparison of latency for entering to the dark compartment before and at the 3, 24, 48 and 72 hours after receiving the shock in the experimental groups. Data are presented as Mean \pm SEM ( $n=9-10$ in each group). The animals of LPS and 7NI-LPS groups were treated by $1 \mathrm{mg} / \mathrm{kg}$ LPS, $2 \mathrm{~h}$ before the retention phase in passive avoidance test. The animals of $7 \mathrm{NI}$ and $7 \mathrm{NI}$-LPS groups received $30 \mathrm{mg} / \mathrm{kg} 7 \mathrm{NI}$, 30 minutes before saline and LPS respectively. The control group received saline. ${ }^{* *} p<0.01,{ }^{* * *} p<0.001$ compared to control group. ${ }^{++} p<0.01,{ }^{+++} p<0.001$ compared to LPS group. 
compartment at all $3\left(\mathrm{f}_{(1,35)}=19.13 ; \mathrm{p}<0.001\right), 24\left(\mathrm{f}_{(1,35)}=5.99\right.$; $\mathrm{p}<0.05), 48\left(\mathrm{f}_{(1,35)}=4.43 ; \mathrm{p}<0.05\right)$ and $72\left(\mathrm{f}_{(1,35)}=7.98 ; \mathrm{p}<0.01\right)$ hours after receiving shock. The total time spent in dark compartment by the animals LPS group was significantly longer than control group at 3, 24, 48 and 72 hours after receiving shock $(\mathrm{p}<0.01, \mathrm{p}<0.001)$. The total time spent in dark compartment in 7NI and 7NI-LPS groups was significantly lower than LPS group ( $<<0.05$, $p<0.01, p<0.001$ ) but there was no significant difference between control, 7NI and 7NI-LPS groups (Figure 2).

Using two way ANOVA, the results showed that there was also a significant main effects for LPS on the total time spent in light compartment at all $3\left(\mathrm{f}_{(1,30)}=71.09 ; \mathrm{p}<0.001\right)$, $24\left(\mathrm{f}_{(1,30)}=10.45 ; \mathrm{p}<0.01\right), 48\left(\mathrm{f}_{(1,30)}=13.06 ; \mathrm{p}<0.001\right)$ and $72\left(\mathrm{f}_{(1,30)}=19.27 ; \mathrm{p}<0.001\right)$ hours after receiving the shock. $7 \mathrm{NI}$ also significantly affected the total time spent in light compartment at all 3( $\left.\mathrm{f}_{(1,30)}=71.09 ; \mathrm{p}<0.001\right), 24\left(\mathrm{f}_{(1,30)}=8.56\right.$; $\mathrm{p}<0.01), 48\left(\mathrm{f}_{(1,30)}=6.03 ; \mathrm{p}<0.05\right)$ and $72\left(\mathrm{f}_{(1,30)}=12.13\right.$; $\mathrm{p}<0.01$ )hours after receiving the shock. There was a significant interaction between 7NI and LPS on the total time spent in light compartment at all $3\left(\mathrm{f}_{(1,30)}=71.09 ; \mathrm{p}<0.001\right)$, $24\left(\mathrm{f}_{(1,30)}=8.32 ; \mathrm{p}<0.01\right), 48\left(\mathrm{f}_{(1,30)}=5.88 ; \mathrm{p}<0.05\right)$ and $72\left(\mathrm{f}_{(1,30)}=9.14 ; \mathrm{p}<0.01\right)$ hours after receiving the shock. The total time spent in light compartment by the animals which received LPS was lower than the rats of the control group at 3, 24, 48 and 72 hour after receiving the shock $(p<0.001)$ whereas, in the 7NI and 7NI-LPS groups was higher than LPS group ( $p<0.05, p<0.01, p<0.001$ ). No significant difference was observed between control, 7NI and 7NI-LPS groups (Figure 3).

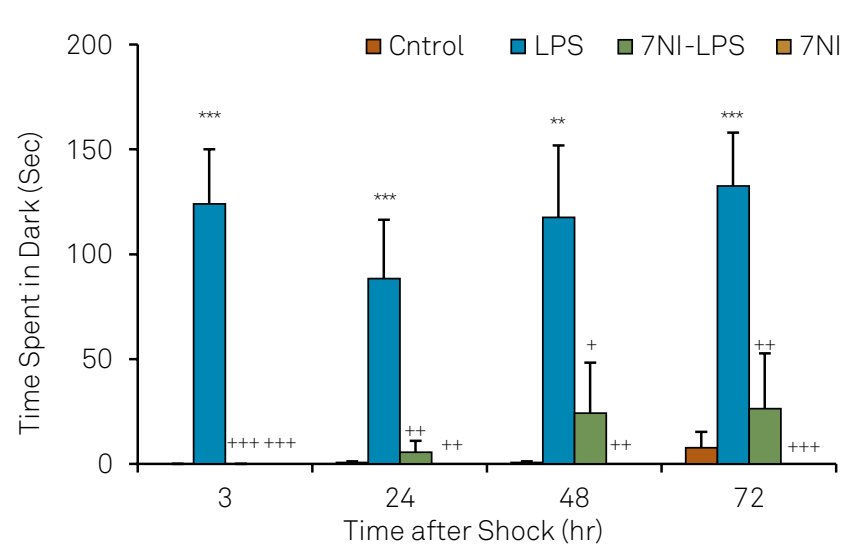

LPS: lipopolysaccharide; 7N1:7-nitroindazole.

Figure 2. Comparison of the total time spent in dark component at 3, 24, 48 and 72 hours after receiving the shock in the experimental groups. Data are presented as Mean \pm SEM ( $n=9-10$ in each group). The animals of LPS and $7 \mathrm{NI}$-LPS groups were treated by $1 \mathrm{mg} / \mathrm{kg}$ LPS, $2 \mathrm{~h}$ before the retention phase in passive avoidance test. The animals of $7 \mathrm{NI}$ and $7 \mathrm{NI}$-LPS groups received $30 \mathrm{mg} / \mathrm{kg} 7 \mathrm{NI}, 30$ minutes before saline and LPS. The control group received saline. ** $p<0.01$, ${ }^{* * *} p<0.001$ compared to control group. ${ }^{+} p<0.05,{ }^{++} p<0.01$, ${ }^{+++} p<0.001$ compared to LPS group.

\section{Biochemical results}

Using two way ANOVA, the results showed that there was a significant main effects for LPS on the MDA concentration in the brain tissues $\left(\mathrm{f}_{(1,35)}=28.57\right.$; $\left.\mathrm{p}<0.001\right)$. 7NI also significantly affected the MDA concentration in the brain tissues $\left(\mathrm{f}_{(1,35)}=56.64 ; \mathrm{p}<0.001\right)$. There was a significant interaction between $7 \mathrm{NI}$ and LPS on the MDA concentration $\left(f_{(1,35)}=23.62 ; p<0.001\right)$. The results also showed that the MDA concentration in the brain tissues of LPS group was higher than the control group ( $p<0.001)$. Injection of $7 \mathrm{NI}$ before LPS decreased MDA concentration in the brain tissues in comparison with LPS group ( $p<0.001$ ) however, there was no significant difference between the control, 7NI and 7NI-LPS groups (Figure 4).

Using two way ANOVA, the results showed that there was a significant main effects for LPS on the total thiol contents in the brain tissues $\left(\mathrm{f}_{(1,35)}=4.08\right.$; $\left.\mathrm{p}<0.05\right)$. 7NI also significantly affected the total thiol contents in the brain tissues $\left(f_{(1,35)}=19.57 ; p<0.01\right)$. There was a significant interaction between $7 \mathrm{NI}$ and LPS on the total thiol contents $\left(\mathrm{f}_{(1,35)}=15.25\right.$; $\mathrm{p}<0.001)$. The total thiol contents in the brain tissues of LPS group was lower than the control group $(\mathrm{p}<0.001)$. Injection of $7 \mathrm{NI}$ increased the total thiol contents in 7NI-LPS group compared with LPS group ( $p<0.001$ ). There was no significant difference between the control, 7NI and 7NI-LPS groups (Figure 5). There were no significant differences in SOD activity in the brain tissues between four groups (Figures 6).

Using two way ANOVA, the results showed that there was a significant main effects for LPS on NO metabolites concentrations in the brain tissues $\left(\mathrm{f}_{(1,18)}=7.68\right.$; $\left.\mathrm{p}<0.05\right)$. 7NI also

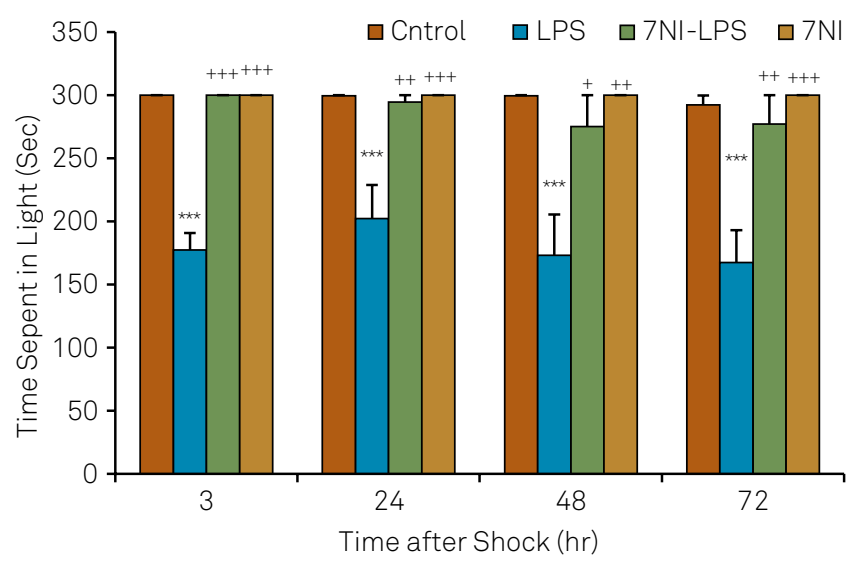

LPS: lipopolysaccharide; 7N1:7-nitroindazole.

Figure 3. Comparison of the total time spent in light component at 3, 24, 48 and 72 hours after receiving the shock in the experimental groups. Data are presented as Mean \pm SEM ( $n=9-10$ in each group). The animals of LPS and $7 \mathrm{NI}$-LPS groups were treated by $1 \mathrm{mg} / \mathrm{kg}$ LPS, $2 \mathrm{~h}$ before the retention phase in passive avoidance test. The animals of $7 \mathrm{NI}$ and $7 \mathrm{NI}$-LPS groups received $30 \mathrm{mg} / \mathrm{kg} 7 \mathrm{NI}, 30$ minutes before saline and LPS respectively. The control group received saline. ${ }^{* * *} p<0.001$ compared to control group. ${ }^{+} p<0.05,{ }^{++} p<0.01$, ${ }^{+++} \mathrm{p}<0.001$ compared to LPS group. 


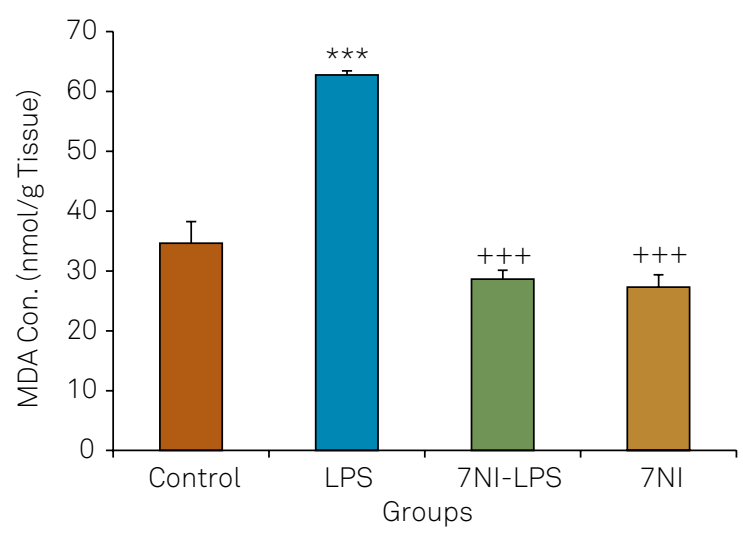

MDA: malondialdehyde; LPS: lipopolysaccharide; 7N1:7-nitroindazole.

Figure 4. Comparison of the MDA concentrations in cortical tissues of four groups. Data are presented as Mean \pm SEM ( $n=9-10$ in each group). ${ }^{* *} p<0.01$ compared to control group. ${ }^{++} p<0.001$ compared to LPS group.

significantly affected NO metabolites concentrations in the brain tissues $\left(f_{(1,18)}=4.02 ; p<0.05\right)$. There was no a significant interaction between 7NI and LPS on the NO metabolites concentrations $\left(f_{(1,18)}=3.25 ; \mathrm{p}>0.05\right)$. NO metabolites concentrations, in the brain tissues of LPS group were higher than control group $(\mathrm{p}<0.05) .7 \mathrm{NI}$ decreased the concentrations of these metabolites in 7NI-LPS group in comparison with LPS group $(\mathrm{p}<0.05)$ however, no significant differences were seen in NO metabolites concentrations between the control, 7NI and 7NI-LPS groups (Figure 7).

\section{DISCUSSION}

In the present study, LPS impaired the passive avoidance memory retention. This finding was supported by decreasing the time latency to enter the dark compartment and

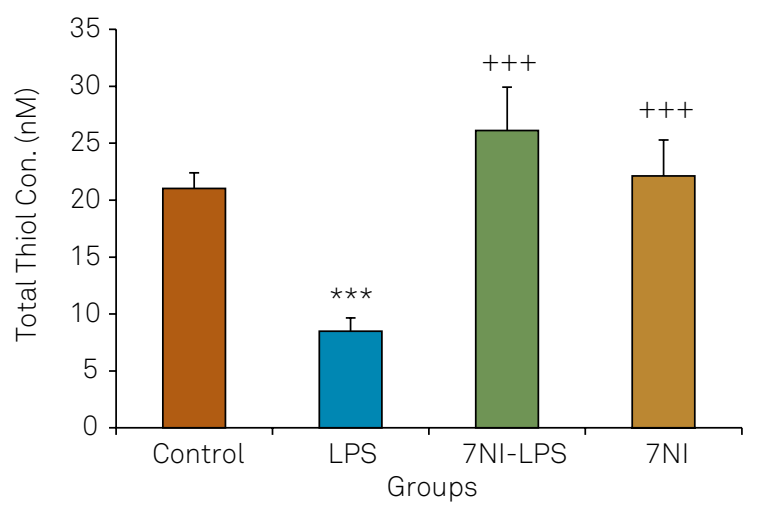

LPS: lipopolysaccharide; 7N1: 7-nitroindazole.

Figure 5. Comparison of the total thiol concentrations in cortical tissues of four groups. Data are presented as Mean \pm SEM ( $n=9-10$ in each group). *** $p<0.01$ compared to control group. ${ }^{+++} p<0.001$ compared to LPS group.

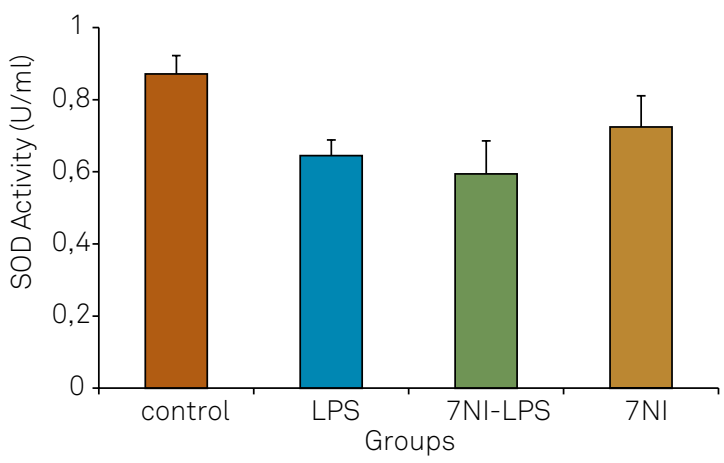

SOD: superoxide dismutase; LPS: lipopolysaccharide; 7N1: 7-nitroindazole.

Figure 6. Comparison of the SOD level in cortical tissues between four groups. Data are shown as Mean \pm SEM ( $n=9-10$ in each group). There is no significant difference between groups.

enhancing the total time spent in dark room and reducing the total time spent in light room in LPS group in comparison with control group. It has been indicated that injection of LPS into the lateral ventricle of the rats brain attenuates memory retention trail ${ }^{21}$. Researcher has also reported that i.p. administration of LPS-induced the passive avoidance memory retention impairment ${ }^{22}$. In an another study, intraperitoneal acute injection of LPS resulted in retention deficit after $24 \mathrm{~h}$ and seventh day of its injection in both of passive avoidance and elevated plus maze tasks ${ }^{23}$. All these findings confirm the results of our study. During inflammation responses, microglia as the principle effectors of immune system in the brain, release pro-inflammatory cytokines which directly affects neuronal function including long-term potentiation, glutamate release and cell signaling pathways ${ }^{24}$. LPS has been shown that triggers the overproduction of pro-inflammatory cytokines such as $\mathrm{TNF}_{\alpha}, \mathrm{IL}_{1 \beta}, \mathrm{IL}-6^{13,25}$. It has also been reported that IL-1 receptors antagonist ameliorates learning and

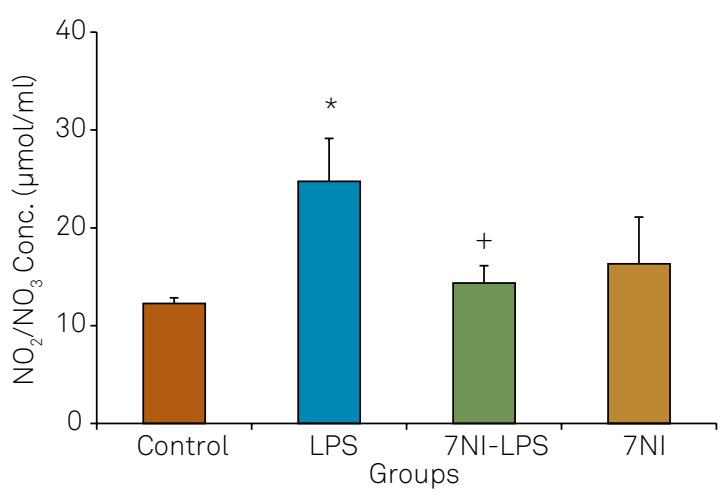

LPS: lipopolysaccharide; 7N1: 7-nitroindazole.

Figure 7. Comparison of the nitric oxide metabolites level in cortical tissues between four groups. Data are shown as Mean \pm SEM ( $n=5-6$ in each group) * $p<0.05$ compared to control group. ${ }^{+} p<0.05$ compared to LPS group. 
memory deficits when it is administrated before LPS ${ }^{26}$. Due to a high density cytokines receptors, hippocampus has been considered to be very vulnerable to inflammation ${ }^{27}$. Using animal models, it has been indicated that administration of cytokines or other immune system stimuli including LPS deteriorate hippocampus-dependent learning and memory process ${ }^{24}$. Recently, the brain tissues oxidative damage was considered to have an important role in deleterious effects of LPS on learning and memory ${ }^{16}$. The cerebral cortex and hippocampus which play crucial roles in learning and cognition have been shown to be very sensitive to the oxidative stress $^{28}$. In our study, the level of MDA increased in LPS group in comparison with the control while, the total thiol contents diminished which confirms the contribution of brain tissues oxidative damage in impairing effects of LPS on memory retention which was seen in the present study. We observed no significant difference in the activity SOD in the brain tissues between groups. It has been previously shown that LPS disturbs the oxidative status and energy metabolism in the brain $^{29}$. In has also been reported that LPS increases the level of MDA and reduces glutathione (GH) while, does not change the activity of SOD ${ }^{30}$.

NO has been shown to act as a cytotoxic agent if its production gets out of control ${ }^{15}$. NO reacts with oxygen species including superoxide $\left(\mathrm{O}_{2}^{-}\right)$to produce peroxynitrite ${ }^{31}$. NO and its derived-oxygen species starts damaging biochemical events including lipid peroxidation, protein oxidation, and oxidation of thiols, which finally lead to activation/deactivation of various enzymatic systems ${ }^{32}$. It has also been reported that LPS triggers the production of hydroxyl radical $(\mathrm{OH} \bullet)$, nitric oxide metabolites ( $\mathrm{NOx})$, superoxide (O2•) and other reactive oxygen/nitrogen species as well as inflammatory cytokines $^{14}$. In contrast, NO as a retrograde messenger plays an essential role in learning and memory processes, although its effects are incompatible ${ }^{6}$. However, other reports confirmed that a several fold concentrations of NO in the brain disturbs the retention of acquired task in rats ${ }^{33}$. In this study, the level of NO metabolites $\left(\mathrm{NO}_{2} / \mathrm{NO}_{3}\right)$ in LPS-treated group was higher than control group. Thus, it is possible that excessive production of NO by probably inducing an oxidative procedure has an important role in LPS-induced memory retention impairment which was seen in the present study. In the present research, besides of prevention of impairing effects of LPS on memory retention, $7 \mathrm{NI}$ prevented the enhancing effect of LPS on the brain levels of $\mathrm{NO}$ metabolites $\left(\mathrm{NO}_{2} / \mathrm{NO}_{3}\right)$ in the animals of 7NI-LPS group compared to LPS group. In agree with our results, it has been shown that i.p. injection of 7-NI reduced zinc-induced cell death in cerebellar Purkinje cells of the rats ${ }^{34}$. In the current study, injection of 7-NI before LPS resulted in a reduction of MDA concentration and enhancement of total thiol concentrations. According to the results of present study, 7NI prevented oxidative damage thus it seems that 7-NI improves memory retention deficits through attenuating of the effect of LPS on brain tissues oxidative damage. Regarding the results of current study, it seems that the impairing effects of LPS on memory retention impairment is partly through inducing the activity of nNOS which is preventable by $7 \mathrm{NI}$ however, all of these mechanisms should be investigated in the future studies.

Finally, it is concluded that overproduction of NO and brain tissues oxidative damage which probably take place following LPS-induced inflammation, are important contributing factors in the effects ofLPS on memory retention impairment. Regarding the protective effect of $7 \mathrm{NI}$ against LPS-induced memory retention impairment in the present study, which was accompanied with improving of oxidative stress criteria and lowering of NO metabolites, the mediatory effects of nNOS could be postulated.

\section{Acknowledgments}

The results described in this paper were from a $\mathrm{PhD}$ student's thesis. The authors would like to thank the Vice Presidency of Research of Mashhad University of Medical Sciences for their financial support.

\section{References}

1. Yan WW, Chen GH, Wang F, Tong JJ, Tao F. Long-term acarbose administration alleviating the impairment of spatial learning and memory in the SAMP8 mice was associated with alleviated reduction of insulin system and acetylated H4K8. Brain Res. 2015;1603:22-31. doi:10.1016/j.brainres.2015.01.042

2. Yirmiya R, Goshen I. Immune modulation of learning, memory, neural plasticity and neurogenesis. Brain Behav Immun. 2011;25(2):181-213. doi:10.1016/j.bbi.2010.10.015

3. Kipnis J, Derecki NC, Yang C, Scrable H. Immunity and cognition: what do age-related dementia, HIV-dementia and 'chemo-brain' have in common? Trends Immunol. 2008;29(10):455-63. doi:10.1016/j.it.2008.07.007

4. Walker L, Sills GJ. Inflammation and epilepsy: the foundations for a new therapeutic approach in epilepsy? Epilepsy Curr 2012;12(1):8-12. doi:10.5698/1535-7511-12.1.8
5. Zarifkar A, Choopani S, Ghasemi R, Naghdi N, Maghsoudi AH, Maghsoudi N et al. Agmatine prevents LPS-induced spatial memory impairment and hippocampal apoptosis. Eur J Pharmacol. 2010;634(1-3):84-8. doi:10.1016/j.ejphar.2010.02.029

6. Guix FX, Uribesalgo I, Coma M, MuÑoz FJ. The physiology and pathophysiology of nitric oxide in the brain. Prog Neurobiol. 2005;76(2):126-52. doi:10.1016/j.pneurobio.2005.06.001

7. Lüth HJ, Münch G, Arendt T. Aberrant expression of NOS isoforms in Alzheimer's disease is structurally related to nitrotyrosine formation. Brain Res. 2002 Oct 25;953(1-2):135-43. doi:10.1016/S0006-8993(02)03280-8

8. Brown GC, Borutaite V. Nitric oxide, cytochrome $\mathrm{c}$ and mitochondria Biochem Soc Symp. 1999;66:17-25.

9. Paul V, Ekambaram P. Involvement of nitric oxide in learning \& memory processes. Indian J Med Res. 2011;133(5):471-8. 
10. Akar F, Mutlu O, Komsuoglu Celikyurt I, Bektas E, Tanyeri P, Ulak G et al. Effects of 7-NI and ODQ on memory in the passive avoidance, novel object recognition, and social transmission of food preference tests in mice. Med Sci Monit Basic Res. 2014;20:27-35. doi:10.12659/MSMBR.890438

11. Yu SY, Zhang M, Luo J, Zhang L, Shao Y, Li G. Curcumin ameliorates memory deficits via neuronal nitric oxide synthase in aged mice. Prog Neuropsychopharmacol Biol Psychiatry. 2013;45:47-53. doi:10.1016/j.pnpbp.2013.05.001

12. Yildiz Akar F, Ulak G, Tanyeri P, Erden F, Utkan T, Gacar N. 7-Nitroindazole, a neuronal nitric oxide synthase inhibitor, impairs passive-avoidance and elevated plus-maze memory performance in rats. Pharmacol Biochem Behav. 2007;87(4):434-43. doi:10.1016/j.pbb.2007.05.019

13. Bak MJ, Truong VL, Kang HS, Jun M, Jeong WS. Anti-inflammatory effect of procyanidins from wild grape (Vitis amurensis) seeds in LPS-induced RAW 264.7 cells. Oxid Med Cell Longev. 2013;2013:409321. doi:10.1155/2013/409321

14. Hou CC, Lin H, Chang CP, Huang WT, Lin MT. Oxidative stress and pyrogenic fever pathogenesis. Eur J Pharmacol. 2011;667(1-3):6-12. doi:10.1016/j.ejphar.2011.05.075

15. Yamada K, Komori Y, Tanaka T, Senzaki K, Nikai T, Sugihara $\mathrm{H}$ et al. Brain dysfunction associated with an induction of nitric oxide synthase following an intracerebral injection of lipopolysaccharide in rats. Neuroscience. 1999;88(1):281-94. doi:10.1016/S0306-4522(98)00237-1

16. Pourganji M, Hosseini M, Soukhtanloo M, Zabihi H, Hadjzadeh MA. Protective role of endogenous ovarian hormones against learning and memory impairments and brain tissues oxidative damage induced by lipopolysaccharide. Iran Red Crescent Med J. 2014;16(3):e13954. doi:10.5812/ircmj.13954

17. Naghibi SM, Hosseini M, Khani F, Rahimi M, Vafaee F, Rakhshandeh $\mathrm{H}$ et al. Effect of aqueous extract of Crocus sativus L. on morphine-induced memory impairment. Adv Pharmacol. Sci. 2012;2012:494367. doi:10.1155/2012/494367

18. Khodabandehloo F, Hosseini M, Rajaei Z, Soukhtanloo M, Farrokhi E, Rezaeipour M. Brain tissue oxidative damage as a possible mechanism for the deleterious effect of a chronic high dose of estradiol on learning and memory in ovariectomized rats. Arq Neuropsiquiatr. 2013;71(5):313-9. doi:10.1590/0004-282X20130027

19. Azizi-Malekabadi H, Hosseini M, Soukhtanlo M, Sadeghian R, Fereidoni M, Khodabandehloo F. Different effects of scopolamine on learning, memory, and nitric oxide metabolite levels in hippocampal tissues of ovariectomized and Sham-operated rats. Arq Neuropsiquiatr. 2012;70(6):447 doi:10.1590/S0004-282X2012000600012

20. Sadeghian R, Fereidoni M, Soukhtanlo M, Azizi-Malekabadi H, Hosseini M. Decreased nitric oxide levels in the hippocampus may play a role in learning and memory deficits in ovariectomized rats treated by a high dose of estradiol. Arq Neuropsiquiatr. 2012;70(11):874-9. doi:10.1590/S0004-282X2012001100010

21. Lee B, Sur B, Park J, Kim SH, Kwon S, Yeom M, et al. Ginsenoside rg3 alleviates lipopolysaccharide-induced learning and memory impairments by anti-inflammatory activity in rats. Biomol Ther (Seoul). 2013;21(5):381-90. doi:10.4062/biomolther.2013.053

22. Rostami F, Oryan S, Ahmadiani A, Dargahi L. Morphine preconditioning protects against LPS-induced neuroinflammation and memory deficit. J Mol Neurosci. 2012;48(1):22-34. doi:10.1007/s12031-012-9726-4

23. Jain NK, Patil CS, Kulkarni SK, Singh A. Modulatory role of cyclooxygenase inhibitors in aging- and scopolamine or lipopolysaccharide-induced cognitive dysfunction in mice. Behav Brain Res. 200218;133(2):369-76. doi:10.1016/S0166-4328(02)00025-6

24. Czerniawski J, Miyashita T, Lewandowski G, Guzowski JF. Systemic lipopolysaccharide administration impairs retrieval of context-object discrimination, but not spatial, memory: evidence for selective disruption of specific hippocampus-dependent memory functions during acute neuroinflammation. Brain Behav Immun. 2015;44:159-66. doi:10.1016/j.bbi.2014.09.014

25. Dantzer R, O'Connor JC, Freund GG, Johnson RW, Kelley KW. From inflammation to sickness and depression: when the immune system subjugates the brain. Nat Rev Neurosci. 2008;9(1):46-56. doi:10.1038/nrn2297

26. Barrientos RM, Higgins EA, Sprunger DB, Watkins LR, Rudy JW, Maier SF. Memory for context is impaired by a post context exposure injection of interleukin-1 beta into dorsal hippocampus. Behav Brain Res. 2002;134(1-2):291-8. doi:10.1016/S0166-4328(02)00043-8

27. Schöbitz B, Voorhuis DA, De Kloet ER. Localization of interleukin 6 mRNA and interleukin 6 receptor mRNA in rat brain. Neurosci Lett. 1992;136(2):189-92. doi:10.1016/0304-3940(92)90046-A

28. Richardson JS. Free radicals in the genesis of Alzheimer's disease. Ann N Y Acad Sci. 1993;695(1):73-6. doi:10.1111/j.1749-6632.1993.tb23031.x

29. Sewerynek E, Melchiorri D, Chen L, Reiter RJ. Melatonin reduces both basal and bacterial lipopolysaccharide-induced lipid peroxidation in vitro. Free Radic Biol Med. 1995;19(6):903-9. doi:10.1016/0891-5849(95)00101-3

30. Kheir-Eldin AA, Motawi TK, Gad MZ, Abd-ElGawad HM. Protective effect of vitamin $\mathrm{E}$, beta-carotene and $\mathrm{N}$-acetylcysteine from the brain oxidative stress induced in rats by lipopolysaccharide. Int J Biochem Cell Biol. 2001;33(5):475-82. doi:10.1016/S1357-2725(01)00032-2

31. Ischiropoulos H, Zhu L, Beckman JS. Peroxynitrite formation from macrophage-derived nitric oxide. Arch Biochem Biophys. 1992;298(2):446-51. doi:10.1016/0003-9861(92)90433-W

32. Luperchio S, Tamir S, Tannenbaum SR. NO-induced oxidative stress and glutathione metabolism in rodent and human cells. Free Radic Biol Med. 1996;21(4):513-9. doi:10.1016/0891-5849(96)00219-5

33. Reis EA, Oliveira LS, Lamers ML, Netto CA, Wyse AT. Arginine administration inhibits hippocampal $\mathrm{Na}(+), \mathrm{K}(+)$-ATPase activity and impairs retention of an inhibitory avoidance task in rats. Brain Res. 2002;951(2):151-7. doi:10.1016/S0006-8993(02)03077-9

34. Gökçe MF, Kaplan S, Türkkani A, Kozan R, Ayyildiz M, Emirzeoglu M et al. Nitric oxide synthase inhibitors protect cerebellar Purkinje cells from zinc-induced cell loss in adult rat. J Chem Neuroanat. 2011;41(1):25-31. doi:10.1016/j.jchemneu.2010.10.004 